Robert Yergeau est né à Cowansville en 1956. Etudes collegiales et universitaires à Sherbrooke. A publié cinq recueils de poèmes: l'Oralité de l'émeute (Naaman, 1989), Présence unanime (Editions de l'Université d'Ottawa, 1981), Déchirure de l'ombre (Noroît, 1982), l'Usage du réel (Noroît, 1986) et le Tombeau d'Adélina Albert (Noroit, 1987). Critique de poésie à University of Toronto Quarterly. Enseigne au département des lettres françaises de l'Université d'Ottawa.

\title{
Prière pour un fantôme (extraits)
}

\section{Partir}

Partir, c'est vaincre

En quel pays vaincras-tu la beauté si elle ne te vainc pas?

La vie, l'âme et le corps n'existent pas seuls les fantômes viennent nous hanter

J'ai cru que l'espoir viendrait de toi que j' ai aimé jusqu'au mensonge 


\section{Fuir}

Et la beauté un jour reniera ta beauté

Le soleil sera une blessure

Sur tes lèvres sans ombre

Avance à découvert

Mais les larmes bientôt ne suffiront plus

Il n'y a que la solitude sans le prix de la solitude

Croire et aimer est à ce prix

Hauteur sur laquelle tu ne t'établis plus

Ainsi seras-tu vivante

Et morte pour moi

Lumière inquiétante pour notre éternité

\section{3 juillet 1990}

Regretterai-je ce jour de diamant brut

et la chute du temps dans la nuit suicidée

Je serai sans pitié pour moi-même

Viens. Approche-toi un peu plus près de mon sang.

Comme ta voix me fait frissonner.

Pour notre combat sans merci

tenons-nous debout

à flanc d'amertume et de désespoir 


\section{La douceur de vivre}

Le soir tremble

Nous sommes encore étonnés par la beauté des choses

$\mathrm{Tu}$ as soif

Un peu d'eau sur tes lèvres recrée l'unité de la mer

Et cette façon que possède ton corps

de retenir la lumière et la solitude

à l'heure où la beauté préfigure un monde

où l'évocation même de la beauté sera abjecte

Tu sais qu'il y aura d'autres massacres entre nous

d'autres guerres

d'autres suppliciés sur la ligne de feu du temps

Tu sais que nous mourrons

là où l'on ne devrait jamais mourir

dans une maison paisible

au bout d'une nuit sans destin

Nous vivons loin de nos yeux

avant d'être déchiquetés par les larmes

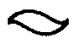

Nous nous reconnaîtrons jusqu'à l'oubli

J'aurai à coeur d'être fidele au rendez-vous

que tu ne m'auras pas fixé

La réalitê rend toujours ses noyés

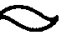




\begin{abstract}
Aujourd'hui
dans un jardin squelettique

dans une ville aux destins saccagés

notre amour a perdu tout son sang

Cowansville, miroir mélancolique

qui me fait espérer la lumière aveugle

des grands fonds urbains
\end{abstract}

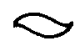

Le moment est venu

nous nous détruisons

rapprochant nos mains d'un impossible centre

nous défaisons nos yeux larme après larme

nous n'aurons pas eu d'enfance ni de mort

nos ombres n'auront plus qu'elles-mêmes pour se rappeler de nous

nous porterons nos corps comme seuls les amnésiques savent le faire

\title{
L'apaisement
}

A l'heure d'éteindre les derniers feux du coeur

le ciel apparaît immense

Tu aimais Dieu

qui ne donne aucune raison

de vaincre le temps

Je sais que tu ressusciteras encore plusieurs fois

dans les bras de ceux qui ne ressusciteront jamais 